A NEW DIETARY PARADIGM?

\title{
Low-carbohydrate and high-fat intake can manage obesity and associated conditions: Occasional survey
}

\author{
T D Noakes
}

Professor Noakes is Director of the UCT/MRC Research Unit for Exercise and Sports Science in the Department of Human Biology, University of Cape Town and the Sports Science Institute of South Africa, Cape Town, South Africa

Corresponding author: T D Noakes (timothy.noakes@uct.ac.za)

This study analyses 127 communications from individuals self-reporting their weight change following adoption of a low-carbohydrate, high-fat (LCHF) eating plan. Total combined self-reported weight loss was $1900 \mathrm{~kg}$ (range $5 \mathrm{~kg}$ gain to $84 \mathrm{~kg}$ loss). The mean \pm standard deviation weight loss of $15( \pm 12) \mathrm{kg}$ is among the largest yet described. Sixteen subjects reported the LCHF 'cured' (i.e. medications no longer required) one or more of their medical conditions, most commonly type 2 diabetes mellitus (T2DM) ( $n=14)$, hypertension $(n=8)$ and hypercholesterolaemia $(n=7)$. Another 9 subjects with either type 1 diabetes mellitus or T2DM reduced medications as did 7 patients with hypertension; 8 no longer suffered from irritable bowel syndrome. These data show that significant and rapid weight loss is possible on an unsupervised eating plan that severely restricts daily carbohydrate intake to approximately $<75 \mathrm{~g} /$ day. Better weight loss on a carbohydrate-restricted LCHF eating plan than on an iso-caloric high-carbohydrate, low-fat (HCLF) diet is well described in the literature, probably due to a paradoxical reduction of hunger by carbohydrate restriction. A randomised controlled clinical trial is urgently required to disprove the hypothesis that the LCHF eating plan can reverse cases of T2DM, metabolic syndrome and hypertension without pharmacotherapy.

S Afr Med J 2013;103(11):826-830. DOI:10.7196/SAMJ.7302

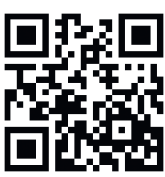

Since William Banting self-published his Letter on Corpulence ${ }^{[1]}$ in 1862, describing how William Harvey ${ }^{[2]}$ had cured Banting's life-long obesity through the avoidance of starchy foods, there has been interest in the low-carbohydrate, high-fat (LCHF) diet for the treatment of obesity.

It was promoted by William Osler in the United States in 1892 as the treatment for obesity ${ }^{[3]}$ and by Vilhjalmur Stefansson who had lived on an exclusive fat/protein diet for more than a decade while living with the Inuit. ${ }^{[4,5]}$ Stefansson's experience inspired a long lineage of LCHF diets in the US. The popularly maligned Atkins diet (1972) ${ }^{[6]}$ is one of the more recent examples.

The 'hormonal' or 'insulin' theory of obesity predicts that the carbohydrate content of the diet must be an important regulator of body mass since 'a functioning pancreas is essential for the fattening process. ${ }^{[7]}$ This theory, originally promoted by German-speaking scientists, also noted that fat accumulated in specific 'lipophilic' areas of the body, more readily in the obese than in the lean. ${ }^{[8]}$ Germany's defeat in World War II with the adoption of English as the universal scientific language, buried this theory until recently. ${ }^{[9-1]}$ Instead, the energy balance model ${ }^{[12]}$ which posits that obesity is due simply to the ingestion of too many calories regardless of macronutrient composition, became the favoured explanation. ${ }^{[9-11]}$

Following a description of my successful adoption of the LCHF diet, ${ }^{[13]}$ I received correspondence from individuals self-reporting their experiences with this eating plan, popularly known in South Africa (SA) as the 'Noakes diet'.

These data have significant limitations; they are self-reported and few have been substantiated so they lack the scientific certainty of a prospective randomised controlled clinical trial (RCT). Nevertheless, they are of value. First, successful weight loss was achieved without expensive medical or other support. Second, subjects lost weight by following a diet that is the opposite of that currently promoted for health, weight loss and the management of type 2 diabetes mellitus (T2DM) in SA. ${ }^{[14]}$ Third, these data suggest that the LCHF has the potential to 'cure' some individuals with morbid obesity, T2DM, hypertension or metabolic syndrome. These findings invite disproof from an appropriately designed RCT.

I received 173 unsolicited communications from individuals selfreporting their experience following adoption of the LCHF eating plan $^{[15]}$ that reduces total daily carbohydrate intake to below $\sim 75 \mathrm{~g} /$ day or lower if required. This analysis is restricted to the 127 communications reporting exact weight losses. Five cases are presented in this paper.

Of the 127 respondents, 41 (32\%) were female. Fig. 1 shows the body weight changes reported by these subjects. Total combined weight loss was $1900 \mathrm{~kg}$. The mean \pm standard deviation weight loss for the total group was $15( \pm 12) \mathrm{kg} ; 16( \pm 12) \mathrm{kg}$ in men and $13( \pm 10) \mathrm{kg}$ in women. One patient with type 1 diabetes mellitus (T1DM) intentionally increased her body weight by $5 \mathrm{~kg}$, at the same time halving her daily insulin requirements; all other subjects lost weight. Symptoms of hunger were reduced or absent on the diet in 27 subjects. Six asserted that their results were either 'life-changing' or 'life-saving'.

Medications were no longer required to treat chronic medical conditions in 16 subjects including: T2DM $(n=14)$, hypertension $(n=8)$ and hypercholesterolaemia $(n=7)$. Some individuals were 'cured' of more than one condition. Another 9 with either T1DM or T2DM reduced their medications, as did 7 patients with hypertension; 8 were 'cured' of irritable bowel syndrome, one after 40 years. Exercise capacity increased markedly in 32 subjects. In one individual, the change was astonishing (Case 5). Five subjects reporting apparently 'miraculous outcomes' are briefly described with their permission.

\section{Case 1}

A 44-year-old Cape Town man was unable to fit into an economy class airplane seat. During the flight, the adjacent passenger complained 
incessantly about his large size. 'Depressed, embarrassed and ashamed' he drove directly from the airport to his general practitioner (GP) who found his blood pressure $(160 / 100 \mathrm{mmHg})$ and blood glucose concentration to be raised. She advised immediate treatment for both conditions and to consult a dietician. He declined, searched the internet, discovered the 'Noakes diet' and decided to adopt it.

His weight loss began immediately and continued for 7 months, during which time he lost $84.6 \mathrm{~kg}$. After 6 months, his GP failed to recognise him. His blood pressure and fasting blood glucose and cholesterol concentrations had reverted to the normal range (Table 1).

He concluded that the LCHF diet had 'saved his life' and that 'label reading has opened my eyes to the almost criminal levels of carbs in everyday processed foods and the propensity of these foods to cause weight gain' (personal communication, 19 March 2013).

\section{Case 2}

A 44-year-old male restaurant critic who had always been 'fat' as a child, never participating in sports or exercise, reached the weight of $153 \mathrm{~kg}$ in October 2011. He had associated complications of T2DM and was receiving treatment for hypertension. He required nonsteroidal anti-inflammatory drugs for relief of intermittent bilateral lower limb and chronic low-back pain. He had tried several methods of weight loss without lasting success. He sought bariatric surgery, but was refused as he posed too great an anaesthetic risk. As a final resort he decided to try the 'Noakes diet'.

Over the next 18 months, he lost $73 \mathrm{~kg}$, at the same time curing his T2DM, hypertension (Table 1), neuropathy and chronic low-back pain. He is now a regular exerciser with a resting heart rate of $45 \mathrm{bpm}$ compared to $80 \mathrm{bpm}$ a year previously. He takes no medications.

Despite a dramatic reduction in calorie intake, his food cravings have disappeared: 'I totally subscribe to the view that sugar and carbohydrates are drugs to the body. I was an addict' (personal communication, 22 April 2013).

\section{Case 3}

A 57 year-old rural GP played rugby and athletics at school and was lean while at university $(78 \mathrm{~kg}$; body mass index (BMI) $21 \mathrm{~kg} / \mathrm{m}^{2}$ ). His wife's

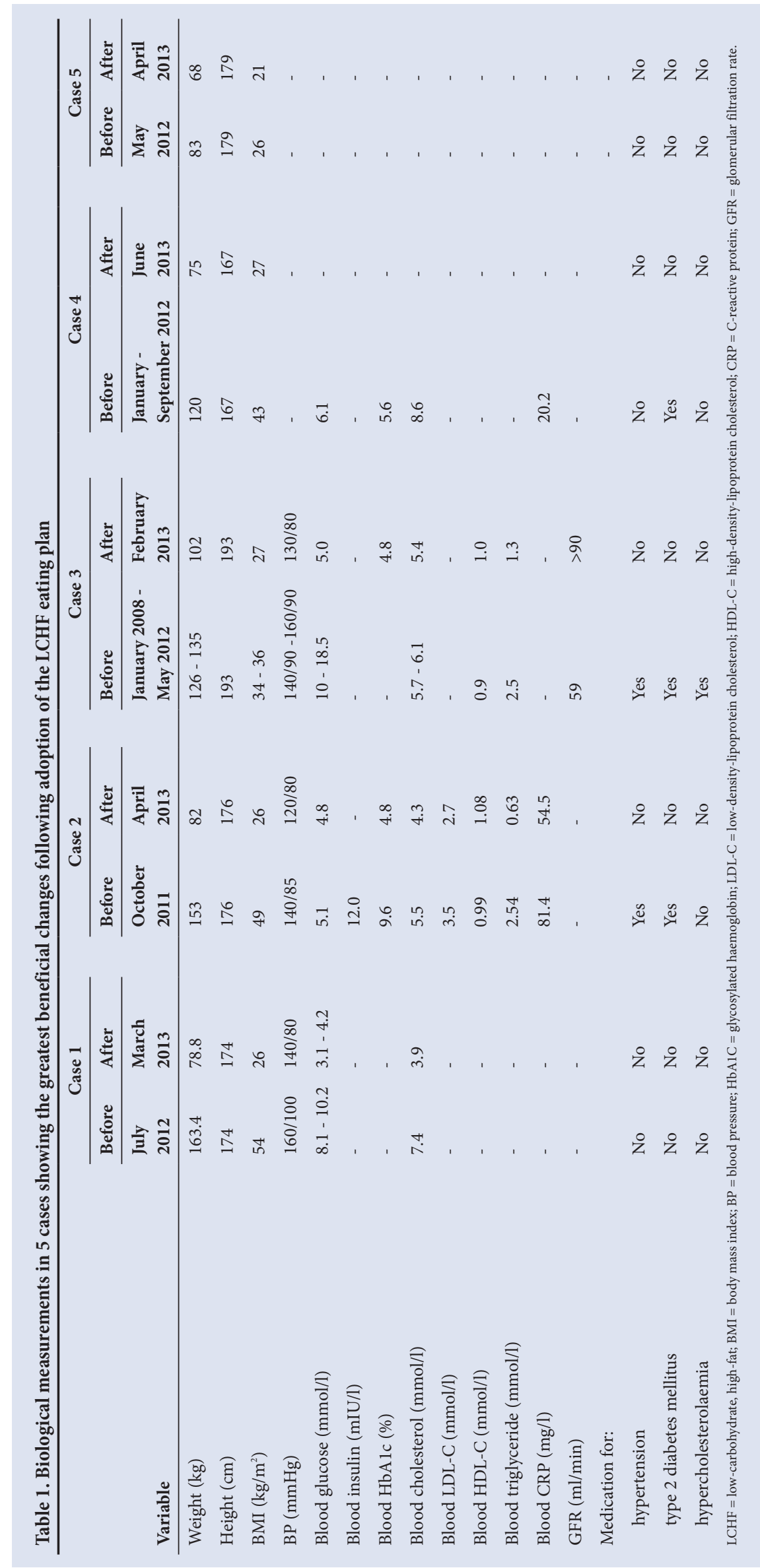


culinary skills, his love of 'healthy' fruits and forced inactivity due to a knee injury at age 34 , resulted in progressive weight gain, reaching $135 \mathrm{~kg}$ in January 2008. He had developed T2DM, hypertension, atrial fibrillation, hypercholesterolaemia, sleep apnoea, fatigue and stucco keratosis. $\mathrm{He}$ was treated with perindopril, bisoprolol, amlodipine and metformin and advised to follow a conventional low-calorie, highcarbohydrate, low-fat (HCLF) (Weight Watcher's) diet. Although he lost $10 \mathrm{~kg}$, he was perpetually hungry. He developed diabetic neuropathy and gout and his hypercholesterolaemia worsened, and we was placed on additional medications gliclazide, rosuvastatin and warfarin. In early 2012, he informed his wife that he was unlikely to live beyond age 65 .

In May 2012 he read about the 'Noakes diet', concluded that he was carbohydrate intolerant and would benefit from the LCHF eating plan. Over the next 8 months, he lost $25 \mathrm{~kg}$, curing all his medical conditions (Table 1). He now offers the LCHF dietary option for all his patients suffering from any of the conditions, of which he is now rid.

\section{Case 4}

Despite regular physical activity, a 23-yearold mother had always struggled with her weight, reaching $73 \mathrm{~kg}$ in grade 9 of high school. At 13 years of age her gall bladder was removed and she was diagnosed with polycystic ovarian syndrome. Weightloss attempts always failed as she would eventually 'cheat', reverting to her addictive food choices, ${ }^{[16]}$ quickly regaining any lost weight. Her health deteriorated and she ceased sport because she was frequently ill.

In the third trimester of her first pregnancy in March 2012, her weight reached $96 \mathrm{~kg}$ and she developed gestational diabetes and hypertension, requiring caesarean section due to uncontrolled hypertension. After the birth of her child, she began to eat addictively. Her weight increased to $120 \mathrm{~kg}$, her surgical wound became infected and she suffered frequent and repeated skin infections culminating in a facial cellulitis that responded only to intravenous clindamycin. She was diagnosed with T2DM and treated with metformin.

She adopted the 'Noakes diet' and by June 2013 her weight had dropped to $75 \mathrm{~kg}$, a loss of $45 \mathrm{~kg}$. She no longer requires medication for T2DM and concluded that '... for the life of me I don't know why I struggled so much (to control my weight) since it really isn't that difficult. It was more of a lifestyle change for me than a diet' (personal communication, 3 June 2013).

\section{Case 5}

A 37-year-old science correspondent, who initially weighed $75 \mathrm{~kg}$ at university and was a competitive athlete, reported that his weight increased to $80 \mathrm{~kg}$ by the time he was age 25 years - despite competitive running. This weight gain caused skin chaffing and painful knees - in spite of which he managed $70 \mathrm{~km} /$ week in training. He participated regularly in marathons and ultra-marathons completing the Two Oceans $56 \mathrm{~km}$ ultra-marathon in between 5h:55min and 6h:45min. In October 2011, he decided to lose weight by completing 9 marathons in 9 provinces in 9 consecutive weeks. However, rather than losing weight, his weight increased to $83 \mathrm{~kg}$ and he ran poorly. In April 2012, he completed the Two Oceans ultra-marathon in his slowest-ever time (6h:57min:57sec) in 7 668th place.

He began the 'Noakes diet' on 11 June 2012. Fig. 2 shows his weight and distance training. He lost the most weight when he ran the least. His racing performances improved dramatically. On 16 March 2013, he completed the Two Oceans ultra-marathon in 3:59:42 in 208th position, nearly 3 hours and 7460 positions better than his performance 12 months earlier. He concluded: 'This is the important point to all of this. The weight loss enabled my training, not the other way around. I feel like I have won my life back' (personal communication, 27 April 2013).

\section{Discussion}

The study has several potential limitations. First, all data are self-reported and were not verified but it is unlikely that all participants

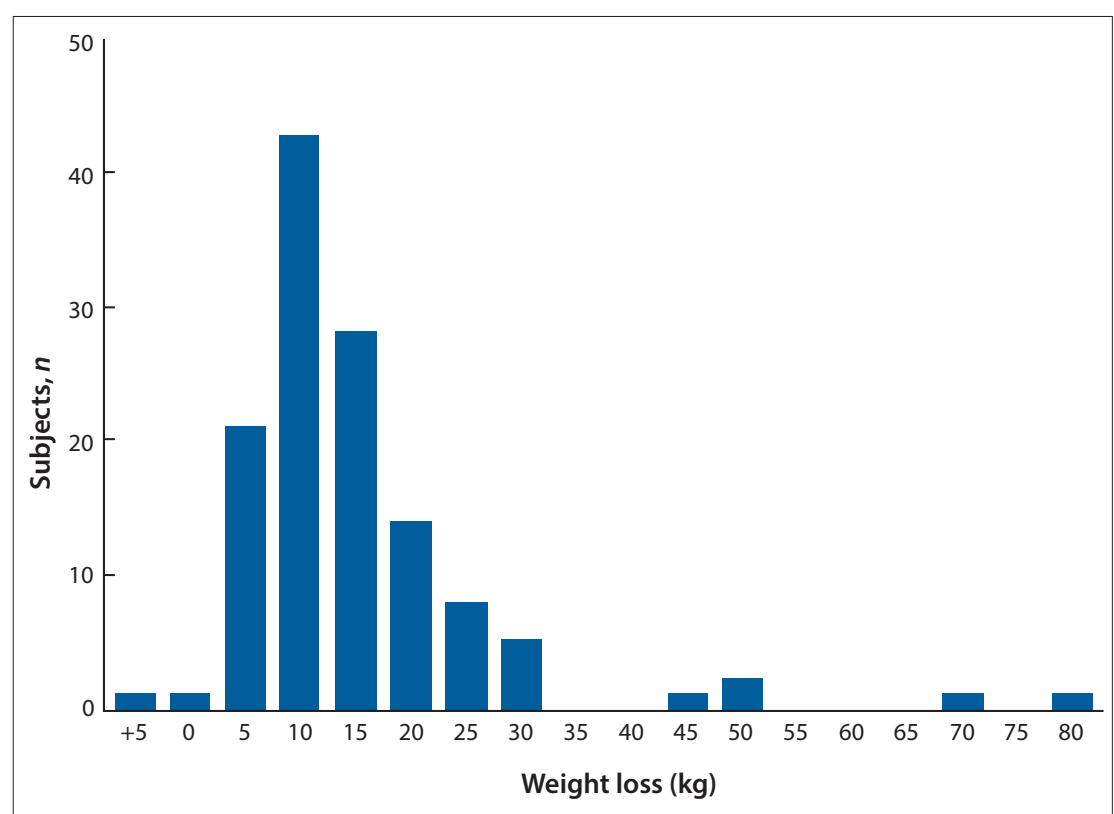

Fig. 1. Distribution of self-reported body weight losses in 127 subjects following adoption of a carbohydrate-restricted, low-carbohydrate, high-fat (LCHF) eating plan. would fabricate this information. Second, there is no record of exactly what each person ate. Third, all reports describe only short-term outcomes. To collect this information as part of an RCT involving 254 subjects would have been very costly.

Despite these substantive limitations, this information challenges current conventional wisdom (widely taught at medical schools); the higher fat content of the LCHF diet (i) must cause weight gain because of the higher energy density (per g) of fat than of either carbohydrate or protein; (ii) will either cause abnormal or worsen already abnormal lipid profiles, and (iii) will worsen blood pressure and blood glucose control. The data also suggest that the macronutrient composition of the diet is the key driver of weight gain and obesity.

Proposition 1: High-fat diets cause weight gain or are inferior to hypocaloric HCLF diets in producing sustained weight loss

The average weight loss $(15 \mathrm{~kg})$ exceeds that reported in expensive clinical trials typically involving the HCLF diet with intensive medical supervision. By comparison, low-fat (HCLF) diets produce an average weight loss of just $1.6 \mathrm{~kg}{ }^{[17]}$ Another study found an average weight loss of $1.3 \mathrm{~kg}$ at 1 year and $0.2 \mathrm{~kg}$ at 2 years. ${ }^{[18]}$ Even an intensive combined diet and physical activity intervention in severe obesity produced an average weight loss of only $\sim 10 \mathrm{~kg}$ at 6 and 12 months. ${ }^{[19]}$ There is extensive evidence that the LCHF is either 'at least as effective ${ }^{\text {'[20] }}$ or more effective ${ }^{[21]}$ than the hypo-caloric HCLF in producing weight loss. 

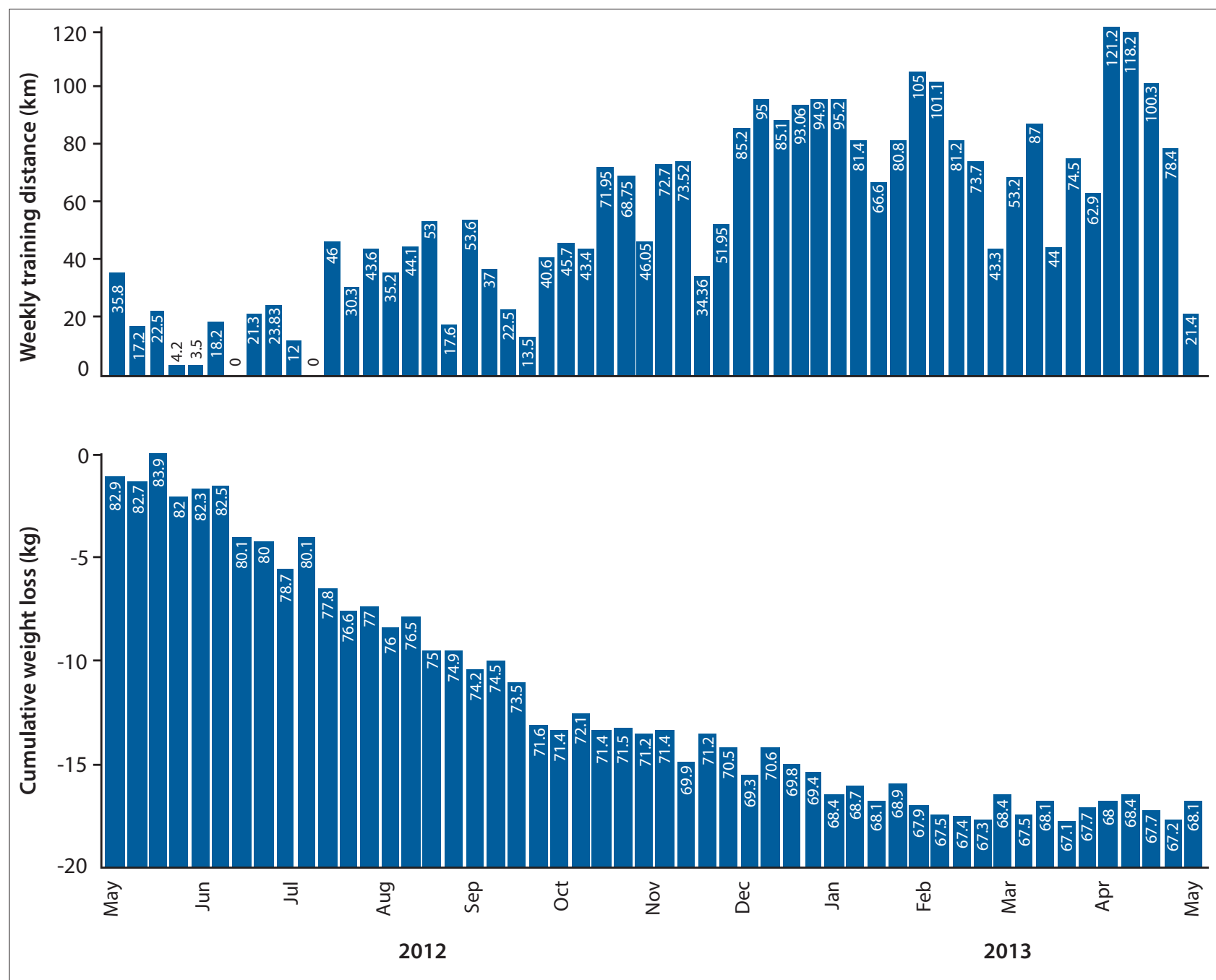

Fig. 2. Case 5. Weekly running training distances (top panel) and cumulative body weight changes (bottom panel). Note that subject lost the most weight when he exercised the least.

The key determinant of long-term successful weight loss is the extent to which any intervention reduces hunger and consequently caloric intake. ${ }^{[6,22-24]}$ Cases 1 and 2 each lost more than $70 \mathrm{~kg}$ without hunger despite eating a fraction of the calories previously needed to satisfy their food cravings. This paradoxical, and important phenomenon was previously reported by Yudkin and Carey. ${ }^{[23]}$ The LCHF diet is especially effective in producing satiation on a reduced energy intake. ${ }^{[6,2]}$ As Yudkin noted, 'the high-fat diet is in fact a low calorie diet.' ${ }^{[24]}$

Proposition 2: A high-fat diet will either cause or worsen abnormal lipid profiles especially in those with hypercholesterolaemia

Five subjects normalised their elevated blood total cholesterol concentrations on the LCHF diet. Meta-analyses confirm that the LCHF is at least as effective ${ }^{[25]}$ as the HCLF in improving all common parameters predicting coronary heart disease (CHD) risk. ${ }^{[20,21,25-29]}$

Besides body weight reduction and normalised blood pressure, this includes greater reductions in parameters of abnormal glucose metabolism, in plasma triglyceride and very-low-density-lipoprotein (VLDL)-cholesterol concentrations, and small dense low-densitylipoprotein (LDL)-cholesterol particle numbers, while significantly increasing plasma high-density-lipoprotein (HDL)-cholesterol concentrations. This occurs without significant increases in LDLcholesterol concentrations. ${ }^{[26]}$ In contrast, a HCLF diet produces changes $^{[30-33]}$ that are considered to be atherogenic.

The evidence that the LCHF produces the greatest benefits in the most unhealthy (Cases 1-4) suggests that the LCHF is the safer option for those who are the most ill. ${ }^{[28,29,31,3,34]}$

Proposition 3: A high-fat diet will elevate blood pressure in those with hypertension and worsen blood glucose control in those with T2DM

Eight subjects reported that the LCHF cured their hypertension; another 7 reduced their anti-hypertensive medications; 14 reported that they no longer require medications to control their blood glucose concentrations indicating that the LCHF 'cured' their T2DM. That the LCHF improves glucose control more effectively than does the HCLF diet is well established in the literature. . $27,3,3,34-36]^{-3}$

The role of sloth and gluttony in the development of obesity and related co-morbidities

The energy balance model of human obesity ${ }^{[9-12,3]}$ predicts that the overweight are consciously slothful and gluttonous. This information shows that many presumed slothful and gluttonous persons have a remarkable capacity to lose weight on the LCHF eating plan. 
Cases 1 - 5 had repeatedly failed to lose weight on a 'healthy' HCLF diet as had many of the others. Only his poor state of health saved Case 2 from bariatric surgery, while Case 3 concluded that he would be dead by age 65 years. Case 4 had never been informed that many processed foods are addictive. ${ }^{[16]}$ Despite much training, the marathon runner (Case 5) gained weight progressively with age. On the LCHF eating plan his weight loss was greatest when he exercised the least (Fig. 2).

If sloth and gluttony alone cause obesity, then none of the respondents should have reversed their obesity as such character defects are presumably immutable.

\section{Summary}

This uncontrolled clinical study describes 127 subjects who collectively lost $1900 \mathrm{~kg}$ while following a diet that is the opposite of that currently prescribed as ideal for weight control and the management of T2DM. ${ }^{[14]}$ This suggests that the dietary cause(s) of obesity require a fundamental re-appraisal. ${ }^{[7-11]} \mathrm{An}$ RCT is urgently needed to disprove the hypothesis that the LCHF diet can reverse T2DM, metabolic syndrome and hypertension without pharmacotherapy.

This report, backed by extensive published evidence, ${ }^{[6,9,20,2,1,23-29,31,34-36,363]}$ suggests that we need to start radically re-thinking the advice that we give to patients. The Swedish National Board of Health and Welfare has concluded that 'low carb diets can today be seen as compatible with scientific evidence and best practice for weight reduction for patients with overweight or diabetes type 2 , as a number of studies have shown effect in the short term and no evidence of harm has emerged .... ${ }^{[39]}$

Acknowledgements. The author's research is funded by Discovery Health, the Medical Research Council, the University of Cape Town and the National Research Foundation including the THRIP programme.

\section{References}

1. Banting W. Letter of Corpulence. 3rd ed. San Francisco: A Roman \& Co., 1865:1-64.

2. Harvey W. On Corpulence in Relation to Disease: With Some Remarks on Diet (1872). London: Henry Renshaw, 1872:1-148.

3. Osler W. The Principles and Practice of Medicine. New York: D Appleton and Company, 1978:2-1079.

4. Stefansson V. The Fat of the Land. New York: The MacMillan Company, 1956:1-339.

5. Stefansson V. The Friendly Arctic. New York: The Macmillan Company, 1921:1-898.

6. Atkins RC. Dr Atkins Diet Revolution. 1st ed. New York: David McKay Company, Inc., 1972:1-310,

7. Falta W. Endocrine Diseases, Including Their Diagnosis and Treatment. 3rd ed. London: J \& A Falta W. Endocrine Dise
Churchill, 1923:1-669.

8. Bauer J. Obesity: Its pathogenesis, etiology and treatment. Arch Intern Med 1941;67(5):968-994.

9. Taubes G. Good Calories, Bad Calories. New York: Anchor Books, 2007:1-609.

10. Taubes G. Why We Get Fat and What to Do About It. New York: Knopf of Random House, 2011:1-257.

11. Taubes G. The science of obesity: What do we really know about what makes us fat? An essay by Gary Taubes. Br Med J 2013;346:13. [http://dx.doi.org/10.1136/bmj.f1050]

12. von Noorden C. Obesity. In: von Noorden C, Hall IW, eds. Metabolism and Practical Medicine. Chicago: Keener, 1907:693-715.

13. Noakes TD, Vlismas M. Challenging Beliefs: Memoirs of a Career. 2nd ed. Cape Town: Zebra Press, 2012:1-392.
14. Catsicas R. The Complete Nutritional Solution to Diabetes. Cape Town: Random House Struik, 2009:1-192.

15. Noakes TD. Tim Noakes on Carbohydrates. Health 24. 11 March 2013. http://www.health24.com/Dietand-nutrition/Nutrition-basics/Tim-Noakes-on-carbohydrates-20120721 (accessed 2 October 2013).

16. Lennerz BS, Alsop DC, Holsen LM, et al. Effects of dietary glycemic index on brain regions related

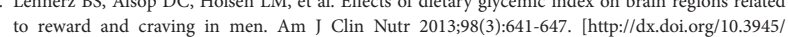
ajcn.113.064113]

17. Hooper L, Abdelhamid A, Moore HJ, et al. Effect of reducing total fat intake on body weight: Systematic review and meta-analysis of randomised controlled trials and cohort studies. Br Med J 2012;345:e7666. [http://dx.doi.org/10.1136/bmj.e7666]

18. Heshka S, Anderson JW, Atkinson RL, et al. Weight loss with self-help compared with a structured commercial program: A randomized trial. JAMA 2003;289(14):1792-1798. [http://dx.doi.org/10.1001 jama.289.14.1792]

19. Goodpaster BH, Delany JP, Otto AD, et al. Effects of diet and physical activity interventions on weight loss and cardiometabolic risk factors in severely obese adults: A randomized trial. JAMA 2010;304(16):1795-1802. [http://dx.doi.org/10.1001/jama.2010.1505]

20. Nordmann AJ, Nordmann A, Briel M, et al. Effects of low-carbohydrate vs low-fat diets on weight loss and cardiovascular risk factors: a meta-analysis of randomized controlled trials. Arch Intern Med 2006;166(3):285-293. [http://dx.doi.org/10.1001/archinte.166.3.285]

21. Bueno NB, de Melo IS, de Oliveira SL, da Rocha AT. Very-low-carbohydrate ketogenic diet y. low-fat diet for long-term weight loss: A meta-analysis of randomised controlled trials. Br J Nutr 2013;110(7):1178-1187. [http://dx.doi.org/10.1017//0007114513000548]

22. Stock AL, Yudkin J. Nutrient intake of subjects on low carbohydrate diet used in treatment of obesity. Am J Clin Nutr 1970;23(7):948-952

23. Yudkin J, Carey M. The treatment of obesity by the 'high fat' diet. The inevitability of calories. Lancet 1960;2(7157):939-941

24. Yudkin J. This Slimming Business. Middlesex, UK: Penguin Books Ltd, 1971:1-208.

25. Hu T, Mills KT, Yao L, et al. Effects of low-carbohydrate diets versus low-fat diets on metabolic risk factors: A meta-analysis of randomized controlled clinical trials. Am J Epidemiol 2012;176(Suppl 7):S44-S54. [http://dx.doi.org/10.1093/aje/kws264]

26. Santos FL, Esteves SS, da Costa PA, Yancy WS, Jr., Nunes JP. Systematic review and meta-analysis of clinical trials of the effects of low carbohydrate diets on cardiovascular risk factors. Obes Rev 2012;13(11):1048-1066. [http://dx.doi.org/10.1111/j.1467-789X.2012.01021.x]

27. Volek JS, Phinney SD, Forsythe CE, et al. Carbohydrate restriction has a more favorable impact on the metabolic syndrome than a low fat diet. Lipids 2009;44(4):297-309. [http://dx.doi.org/10.1007/ s11745-008-3274-2]

28. Volek JS, Phinney SD. A new look at carbohydrate-restricted diets: Separating fact from fiction. Nutr Today 2013;48(2):E1-E7. [http://dx.doi.org/10.1097/NT.0b013e31828814eb]

29. Paoli A, Rubini A, Volek JS, Grimaldi KA. Beyond weight loss: A review of the therapeutic uses of verylow-carbohydrate (ketogenic) diets. Eur J Clin Nutr 2013;67(8):789-796. [http://dx.doi.org/10.1038/ ejcn.2013.116]

30. Krauss RM, Blanche PJ, Rawlings RS, Fernstrom HS, Williams PT. Separate effects of reduced carbohydrate intake and weight loss on atherogenic dyslipidemia. Am J Clin Nutr 2006;83(5):1025-1031.

31. Volek JS, Fernandez ML, Feinman RD, Phinney SD. Dietary carbohydrate restriction induces a unique metabolic state positively affecting atherogenic dyslipidemia, fatty acid partitioning, and metabolic syndrome. Prog Lipid Res 2008;47(5):307-318. [http://dx.doi.org/10.1016/j.plipres.2008.02.003]

32. Roberts R, Bickerton AS, Fielding BA, et al. Reduced oxidation of dietary fat after a short term highcarbohydrate diet. Am J Clin Nutr 2008;87(4):824-831.

33. Westman EC, Yancy WS, Jr., Olsen MK, Dudley T, Guyton JR. Effect of a low-carbohydrate, ketogenic diet program compared to a low-fat diet on fasting lipoprotein subclasses. Int J Cardio 2006;110(2):212-216. [http://dx.doi.org/10.1016/j.ijcard.2005.08.034]

34. Feinman RD. Fad diets in the treatment of diabetes. Curr Diab Rep 2011;11(2):128-135. [http://dx.doi. org/10.1007/s11892-011-0178-y]

35. Ajala O, English P, Pinkney J. Systematic review and meta-analysis of different dietary approaches to the management of type 2 diabetes. Am J Clin Nutr 2013;97(3):505-516. [http://dx.doi.org/10.3945/ ajcn.112.042457]

36. Hussain TA, Mathew TC, Dashti AA, et al. Effect of low-calorie versus low-carbohydrate ketogenic diet in type 2 diabetes. Nutrition 2012;28(10):1016-1021. [http://dx.doi.org/10.1016/j.nut.2012.01.016]

37. Newburgh LH, Johnston MW. The nature of obesity. J Clin Invest 1930;8(2):197-213. [http://dx.doi org/10.1172/JCI100260]

38. Gardner CD, Kiazand A, Alhassan S, et al. Comparison of the Atkins, Zone, Ornish, and LEARN diets for change in weight and related risk factors among overweight premenopausal women. The $A$ to Z Weight Loss Study: A randomized trial. JAMA 2007;297(9):969-977. [http://dx.doi.org/10.1001/ jama.297.9.969]

39. Low-carb for You. The Swedes are eating more butter! 1 June 2009. http://lowcarb4u.blogspot. com/2009/06/swedes-are-eating-more-butter.html (accessed 2 October 2013). 